\title{
Virtual structural monitoring of wind turbines using Operational Modal Analysis techniques
}

\author{
Emilio Di Lorenzo, a, Simone Manzato", b , Bart Peeters ${ }^{1, c}$, \\ Herman Van der Auweraer ${ }^{1, d}$ \\ ${ }^{1}$ LMS International, RTD Test Division - Interleuvenlaan 68, 3001 Leuven, Belgium \\ a emilio.dilorenzo@Imsintl.com, ${ }^{b}$ simone.manzato@Imsintl.com, ${ }^{\circ}$ bart.peeters@Imsintl.com, \\ d herman.vanderauweraer@Imsintl.com
}

Keywords: Operational Modal Analysis, Wind turbines, Condition monitoring, Damage assessment

\begin{abstract}
Operational Modal Analysis (OMA), also known as output-only modal analysis, allows identifying modal parameters only by using the response measurements of the structures in operational conditions when the input forces cannot be measured. This information can then be used to improve numerical models in order to monitor the operating and structural conditions of the system. This is a critical aspect both for condition monitoring and maintenance of large wind turbines, particularly in the off-shore sector where operation and maintenance represent a high percentage of total costs. Although OMA is widely applied, the wind turbine case still remains an open issue. Numerical aeroelastic models could be used, once they have been validated, to introduce virtual damages to the structures in order to analyze the generated data. Results from such models can then be used as baseline to monitor the operating and structural condition of the machine.
\end{abstract}

\section{Introduction}

The objective of this paper is to apply advanced Operational Modal Analysis (OMA) techniques to predict in advance failures or damages with a monitoring application based on the analysis of modal parameters and their variations in operating conditions. In this way, the risk to have catastrophic failures and cost associated can be significantly reduced. OMA is a technique that allows extracting the modal parameters from vibration response signals. The main difference compared to the traditional experimental modal analysis is that it does not need the measurement of the input forces so that also structures under operating conditions, or in other situations where it is impossible to measure the input forces, can be tested. The information obtained from this analysis can then be used to improve numerical models, to predict the dynamic behavior of new designs, to identify the modal parameters of prototypes and to monitor systems in operating conditions.

The problem associated with the dynamic identification of wind turbines has its roots in 1990 when a special technique known as Natural Excitation Technique (NExT) was developed to estimate modal parameters of wind turbines excited in their operating environment [1]. Although the first application of an OMA methodology was related to a vertical-axis wind turbine, not many other applications to wind turbines were studied later on. The main reason is the fact that most of the OMA assumptions are violated by operating wind turbines. 
With this paper, an advanced OMA technique, the so-called PolyMAX Operational Modal Analysis technique is applied to different set of simulated data obtained introducing virtual damages to the unit under test. The main objective is to predict damages by means of modal parameters variations for condition monitoring and maintenance $(\mathrm{O} \& \mathrm{M})$ purposes. In section 2 the PolyMAX Operational Modal Analysis technique is briefly presented. The NREL offshore 5-MW baseline wind turbine is sketched out in Section 3. Section 4 describes the virtual damages introduced in the wind turbine such as ice on all the blades and unbalanced masses. Finally in Section 5 the mentioned OMA technique is applied to the different load cases.

\section{PolyMAX Operational Modal Analysis}

Several OMA techniques have been developed and evaluated in the past years [2]. In this paper, the PolyMAX method has been selected to perform the operational modal analysis. It has been developed as a polyreference version of the least-squares complex frequency-domain (LSCF) estimation method using a so-called right matrix-fraction model [3].

In case of Experimental Modal Analysis [4], the modal decomposition of an FRF matrix [H( $\omega)]$ is:

$$
[H(\omega)]=\sum_{i=1}^{N} \frac{\left\{v_{i}\right\}\left\langle 1 l_{i}^{T}\right\rangle}{j \omega-\lambda_{i}}+\frac{\left\{v_{i}^{*}\right\}\left\langle l_{i}^{H}\right\rangle}{j \omega-\lambda_{i}^{*}}
$$

where 1 is the number of outputs; $\mathrm{N}$ is the number of modes and half of the system order, * is the complex conjugate operator, ${ }^{\mathrm{H}}$ is the complex conjugate transpose of a matrix, $\left\{v_{i}\right\}$ are the mode shapes, $\left\langle l_{i}^{T}\right\rangle$ are the modal participation factors and $\lambda_{i}$ are the poles.

The input spectra $\left[S_{u u}(\omega)\right]$ and output spectra $\left[S_{y y}(\omega)\right]$ of a system represented by the FRF matrix in (1) are related as:

$$
\left[S_{y y}(\omega)\right]=[H(\omega)]\left[S_{u u}(\omega)\right][H(\omega)]^{H}
$$

In case of operational data, output spectra are the only available information. The deterministic knowledge of the input is replaced by the assumption that the input is white noise.

The PolyMAX algorithm greatly facilitates the operational modal parameter estimation process by producing extremely clear stabilization diagrams, making the pole selection a lot easier by means of estimating unstable poles (i.e. mathematical or noise modes) with negative damping making them relatively easy to separate from the stable poles (i.e. system modes).

\section{NREL offshore 5-MW baseline wind turbine}

In this section the wind turbine model used as test case is described. The NREL offshore 5-MW baseline wind turbine has been developed by the National Renewable Energy Laboratory (NREL) to support concept studies aimed at assessing offshore wind technology. It is a conventional three-bladed upwind variable-speed variable blade-pitch-to-feather-controlled turbine [7]. The main objective is to analyze the global dynamic behavior of the full-scale turbine; for this reason the model has been built 
as simple as possible. The generated model is shown in Figure 1 and it can be divided in three main components:
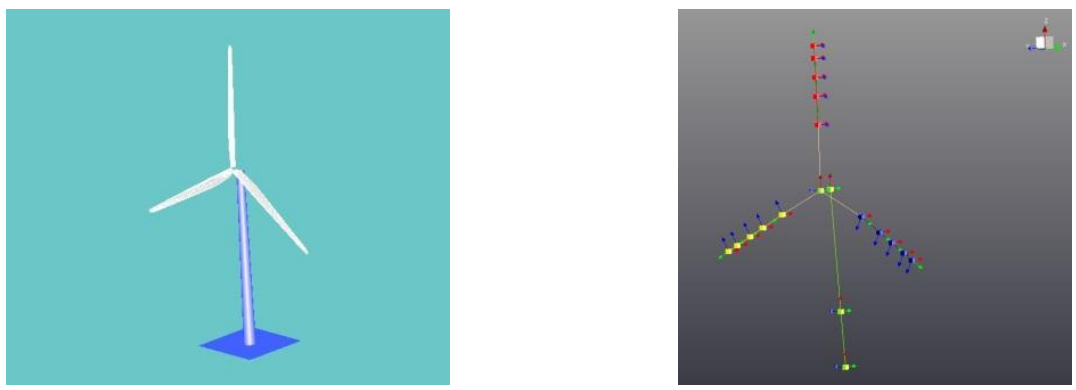

Figure 1: NREL 5 MW S4WT model (left) and Test.Lab geometry (right)

- Tower: it is modeled as 5 elastic beam elements with lumped masses and hinged to the ground foundation. The total tower height is $90 \mathrm{~m}$.

- Rotor: in the 3-bladed rotor, each blade is identical and is modeled with 17 sections with specific mass, elastic and aerodynamic properties.

- Drivetrain: the transmission is simplified into a 1 degree-of-freedom system with a gear ratio of 97 between the Low Speed Shaft (LSS) and the High Speed Shaft (HSS).

The software SAMCEF for Wind Turbines (S4WT) allows the user to define both a structural and an aerodynamic model which are then solved together to obtain the coupled aero-elastic solution [8]. Different parameters can be assigned; in this analysis a turbulent wind has been applied because the interest of the analysis lays in the turbine dynamic response in real conditions. The wind main component is in the X direction (in the model, from LSS to HSS), but to have a more realistic response also turbulent fluctuations on the other two directions are included.

Table 1: Wind turbine main parameters

\begin{tabular}{|l|c|}
\hline Blade Length & $61.5 \mathrm{~m}$ \\
\hline Blade Overall Mass & $17740 \mathrm{Kg}$ \\
\hline Tower Height above Ground & $87.6 \mathrm{~m}$ \\
\hline Tower Overall Mass & $347460 \mathrm{~kg}$ \\
\hline Gearbox Ratio & $97: 1$ \\
\hline
\end{tabular}

\section{Load cases}

The model of the wind turbine is analyzed in different operating conditions and the modal parameters are extracted from the generated acceleration signals by means of Operational Modal Analysis. The different models are solved in S4WT and accelerations are computed and exported in LMS Test.Lab for processing and identification [9].

In order to have simulated accelerations that can be considered as accelerations obtained from tri-axial accelerometers mounted on the blades, it is necessary to consider them in the local reference frame in 
which the $\mathrm{X}$ axis is the blade axis (oriented toward the blade tip), the $\mathrm{Y}$ axis is aligned with the chordline and belongs to the blade section plane (oriented toward the leading edge) and the $\mathrm{Z}$ axis is normal to the chord line and belongs to the blade section plane. Using this axis configuration, the edge-wise modes are described by bending along the $\mathrm{Y}$ axis while flap-wise modes bend the structure along the $\mathrm{Z}$ axis. Axial modes along the blade pitch axis can be neglected since they appear at frequencies much higher than those the analysis will focus on in this paper.

Different locations are selected to measure the accelerations; three sensors distributed along the tower, one sensor at the hub center and five sensors per-blade located on the pitch axis.

After analyzing the response of the structure in reference and ideal conditions, different possible damages will be introduced to understand how they affect the measured accelerations. In this preliminary assessment, two main damages are introduced consisting of the ice formation on the blades and the presence of a mass unbalance on a blade. The presence of ice on the blades can create excessive turbine vibration and can change the natural frequencies of the blades as well as increase the fatigue loads. It is very important to predict when the icing phenomena occur. Icing has two main effects [10]; on one hand it modifies the blade shape increasing the drag and decreasing the lift and on the other hand the presence of an additional and not uniformly distributed mass could cause unbalancing of the rotor.

Within the software S4WT, the conditions "ice formation on all rotor blades" and "ice formation on all rotor blades except one" can be investigated. The mass distribution (mass/unit length) is assumed at the leading edge of the rotor blade and it increases linearly from zero at the rotor axis to the maximum value $\mu_{\mathrm{E}}$ at half the radius and then it remains constant up to the outermost radius. The value $\mu_{\mathrm{E}}$ is calculated as:

$$
\mu_{\mathrm{E}}=\rho_{\mathrm{E}} \cdot \mathrm{k} \cdot \mathrm{c}_{\min }\left(\mathrm{c}_{\max }+\mathrm{c}_{\min }\right)
$$

where $\mu_{\mathrm{E}}$ is the mass distribution on the leading edge of the rotor blade at half the rotor radius, $\rho_{\mathrm{E}}$ is the ice density, $\mathrm{R}$ is the rotor radius, $\mathrm{c}_{\max }$ is the maximum chord length and $\mathrm{c}_{\min }$ is the chord length at the blade tip, linearly extrapolated from the blade contour and:

$$
\mathrm{k}=0.00675+0.3 \exp (-0.32 \mathrm{R})
$$

The second damage condition which has been simulated is the presence of an unbalanced mass that is added to a particular location on one of the wind turbine blades. A little cubic mass ( $\mathrm{m}=30 \mathrm{Kg}$ ) placed not far from the rotor center was considered for this preliminary analysis.

\section{Data analysis}

First of all, the wind turbine is analyzed in parked conditions. This load case represents the condition in which the blades are parked and the generator is disconnected; the first seconds are used to place the pitch in its parking position and the rotor at the angle specified as initial rotor angle. At the start time, the rotor is released, but the pitch remains fixed.

Long time histories are usually required for confident modal parameters estimation, but on the other hand a small sampling frequency is necessary to better determine low frequency modes; as a good 
compromise between these requirements and the computational time, the simulations last 700 seconds and the sampling frequency is chosen to be equal to $100 \mathrm{~Hz}$. The interesting modes are at very low frequencies; so a down-sampling to $10 \mathrm{~Hz}$ has been performed in the first part of the analysis.

To perform Operational Modal Analysis, the point at the tower top is chosen as reference for the correlations and spectra computation, which are then used to extract the modal parameters by means of PolyMAX method [11]. To simplify the entire procedure, the accelerations along the blade axis are neglected. The identified modes are then compared to those one obtained using both the FAST model and the ADAMS model; in FAST the natural frequencies are calculated by performing an eigenanalysis on the first-order matrix created from a linearization analysis, while in ADAMS a command that linearizes the complete model and compute eigendata is used.

Table 2: Numerical modes in parked conditions; STS: side-to-side; FA: fore-aft; blade modes are described based on their main motion orientation

\begin{tabular}{|c|l|c|c|c|}
\hline \multirow{2}{*}{ Mode } & \multirow{2}{*}{ Description } & \multicolumn{3}{|c|}{ Natural frequencies [Hz] } \\
\cline { 3 - 5 } & & Test.Lab & FAST & ADAMS \\
\hline $\mathbf{1}$ & $\mathbf{1}^{\text {st }}$ Tower STS & 0.312 & 0.312 & 0.319 \\
\hline $\mathbf{2}$ & $\mathbf{1}^{\text {st }}$ Tower FA & 0.329 & 0.324 & 0.316 \\
\hline $\mathbf{3}$ & $\mathbf{1}^{\text {st }}$ Flap Yaw & 0.666 & 0.666 & 0.630 \\
\hline $\mathbf{4}$ & $\mathbf{1}^{\text {st }}$ Flap Pitch & 0.675 & 0.668 & 0.669 \\
\hline $\mathbf{5}$ & $\mathbf{1}^{\text {st }}$ Flap Sym & 0.720 & 0.700 & 0.702 \\
\hline $\mathbf{6}$ & $\mathbf{1}^{\text {st }}$ Edge Pitch & 1.056 & 1.079 & 1.074 \\
\hline $\mathbf{7}$ & $\mathbf{1}^{\text {st }}$ Edge Yaw & 1.059 & 1.089 & 1.088 \\
\hline $\mathbf{8}$ & $\mathbf{2}^{\text {nd }}$ Flap Yaw & 1.853 & 1.934 & 1.651 \\
\hline $\mathbf{9}$ & $\mathbf{2}^{\text {nd }}$ Flap Pitch & 1.888 & 1.922 & 1.856 \\
\hline $\mathbf{1 0}$ & $\mathbf{2}^{\text {nd }}$ Flap Sym & 1.900 & 2.021 & 1.960 \\
\hline
\end{tabular}

The results are summarized in Table 2 and the agreement between them is quite good. By using PolyMAX all the first 10 modes can be identified and the biggest differences exist in the predictions of the blades second asymmetric flapwise yaw and pitch modes. "Yaw" and "pitch" mean that these blade asymmetric modes couple with the nacelle-yaw and nacelle-pitching motions, respectively.

The natural frequencies shown in Table 2 are obtained in the standard configuration; they can be compared to those one obtained in other cases such as that one in which the presence of ice is simulated on all the blades or that one in which the ice is on all the blades but one.

In order to perform a better analysis, the point at the blade root is chosen as reference for the correlations and spectra computation and the blade axis accelerations are neglected. The results, in the form of frequencies and damping values, are shown in Table 3 for some of the modes. A frequency shift due to the added ice mass on the blades can be observed and, as expected, increasing the mass decreases the natural. Not so many considerations can be done regarding the damping values because a global trend cannot be seen moving from one condition to another one, but it should be analyzed mode by mode. Besides, possible effect on damping should be more visible in operating conditions. 
Table 3: Numerical modes in parked conditions for different configurations

\begin{tabular}{|l|c|c|c|c|c|c|}
\hline \multirow{2}{*}{ Mode } & \multicolumn{2}{|c|}{ Standard configuration } & \multicolumn{2}{c|}{ Ice on all the blades } & \multicolumn{2}{c|}{ Ice on all the blades but one } \\
\cline { 2 - 7 } & $\begin{array}{c}\text { Frequency } \\
{[\mathrm{Hz}]}\end{array}$ & $\begin{array}{c}\text { Damping } \\
{[\%]}\end{array}$ & $\begin{array}{c}\text { Frequency } \\
{[\mathrm{Hz}]}\end{array}$ & $\begin{array}{c}\text { Damping } \\
{[\%]}\end{array}$ & $\begin{array}{c}\text { Frequency } \\
{[\mathrm{Hz}]}\end{array}$ & $\begin{array}{c}\text { Damping } \\
{[\%]}\end{array}$ \\
\hline $\mathbf{1}^{\text {st }}$ Tower FA & 0.329 & 5.59 & 0.324 & 5.13 & 0.324 & 5.24 \\
\hline $\mathbf{1}^{\text {st }}$ Flap Yaw & 0.666 & 6.20 & 0.588 & 7.05 & 0.585 & 7.06 \\
\hline $\mathbf{1}^{\text {st }}$ Edge Yaw & 1.059 & 0.75 & 0.948 & 0.95 & 0.948 & 0.99 \\
\hline $\mathbf{2}^{\text {nd }}$ Flap Yaw & 1.853 & 3.24 & 1.696 & 2.05 & 1.695 & 2.33 \\
\hline
\end{tabular}

For a qualitative analysis of the signals, the power spectral density (PSD) from some sensors is computed and shown in Figure 2. One point along each one of the three blades at the same distance from the rotor center is taken into account. The PSD of the time signals are calculated using the Welch's estimator. The data are divided up into smaller blocks to improve the resolution; these blocks are defined by a block size that has a number of time samples. To achieve a high calculation performance, the algorithm requires that the block size be a power of 2; so a value equal to 512 is chosen with an overlapping between the blocks of 50\% to compensate the effects of using Hanning windows in time domain.
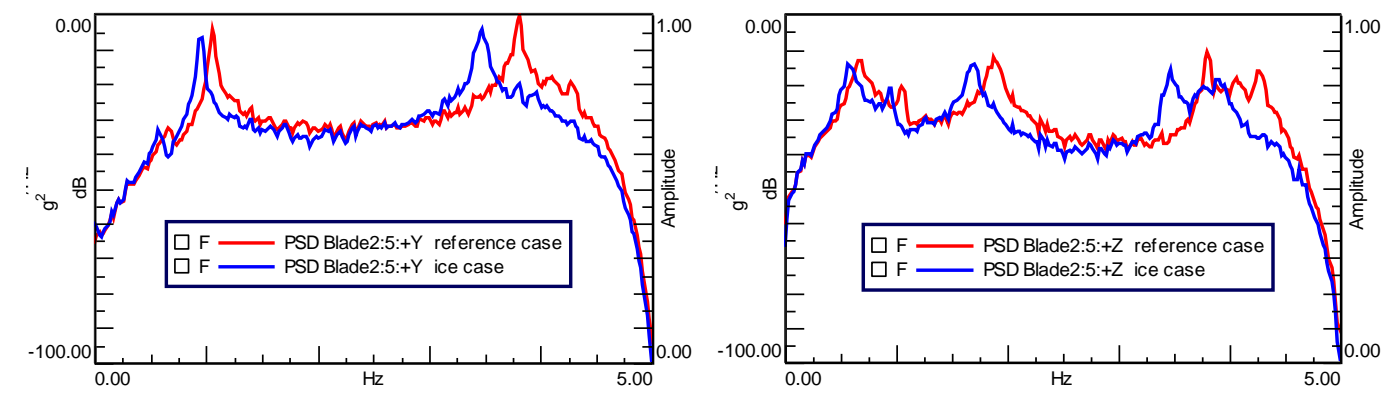

Figure 2: PSDs of acceleration measured on one point on the $2^{\text {nd }}$ blade in parked conditions. Reference case (red curves) compared to the one with ice on the blade (blue curves)

First of all, parked conditions are analyzed. Two different configurations are considered, the standard one and that one with ice formation on all the blades. The curves are shown in Figure 2. Almost all peaks for the blade with ice are shifted to lower frequencies, as a consequence of the mass increase, both in $\mathrm{Y}$ and $\mathrm{Z}$ directions.

Figure 3 and Figure 4 show the PSDs in operating conditions for different configurations. The fundamental harmonic frequency is $0.217 \mathrm{~Hz}$ because of an averaged rotational speed equal to 13.02 rpm. The PSD amplitude decreases for ice configuration in comparison with the reference case; the same considerations can be done regarding the mass unbalance configuration, also if the blade mass is quite bigger than the unbalanced mass and the differences between the two curves are not so evident. Figure 3 compares the reference case with the one with ice on all blades but one (the blade without ice is the $3^{\text {rd }}$ blade); in this case the peaks shift can be seen for the real modes, while the harmonics remain 
at a fixed frequency. Two resonances around $1.10 \mathrm{~Hz}$ and $3.75 \mathrm{~Hz}$ can be identified in operating conditions; they should correspond to the first and second edgewise modes.
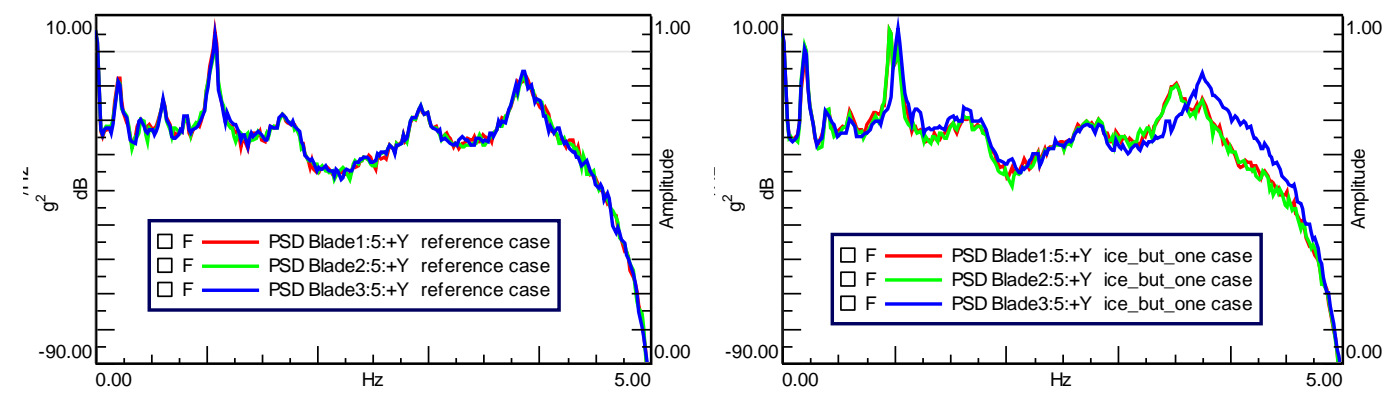

Figure 3: PSDs of acceleration measured on one point on each blade in operating conditions. Reference case (left) compared to ice on all blades but one (right)

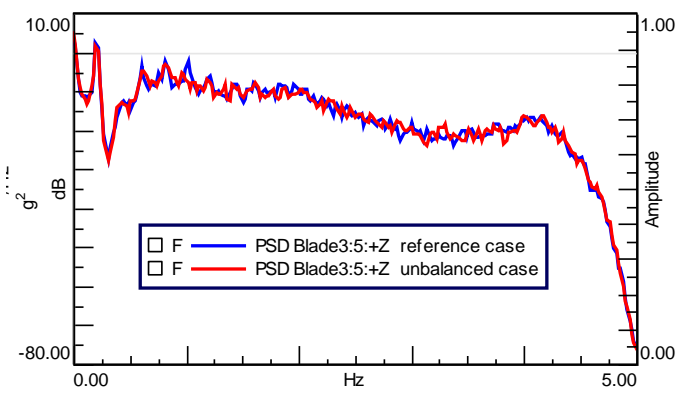

Figure 4: PSDs of acceleration measured on one point on each blade in operating conditions. Reference case (blue curve) compared to mass unbalance case (red curve)

\section{Conclusions}

In this paper, an advanced OMA technique has been applied to a wind turbine to predict in advance failures or damages with a monitoring application based on the analysis of modal parameters and their variations in operating conditions. The simulation model of a wind turbine has been built using an aeroelastic code; first of all, data have been generated for parked conditions and processed using the OMA technique to identify a reference set of modes. Then, different load cases have been considered and data have been processed to analyze the difference in frequency and amplitude from one case to another. For example, adding ice on all the blades causes a frequency shift toward lower frequencies for all the natural frequencies. Then an operating case has been simulated and the data have been processed and analyzed for different conditions, with the icing and with the presence of an unbalanced mass on one of the three blades. In operating conditions, the presence of harmonic components in the signals makes the modal identification process critical because these components have a much higher energy than the ones related to the structural response. In the literature different techniques to separate the components and enhance the identification process have been implemented. In the preliminary study, the harmonics components have not been removed, but in a more detailed study the prediction in advance of failures and damages will be analyzed after using one of the harmonic removal methods. 


\section{Acknowledgments}

The authors acknowledge the European Commission (EC) for their research grant under the project FP7-PEOPLE-2012-ITN 309395 "MARE-WINT" (new MAterials and REliability in offshore WINd Turbines technology), see: http://marewint.eu/.

\section{References}

[1] G.H. James III, T.G. Carne, J.P. Lauffer, The Natural Excitation Technique (NExT) for Modal Parameter Extraction From Operating Wind Turbines, Sandia National Laboratories technical report, USA, February 1993.

[2] B. Peeteers, P. Guillaume, H. Van der Auweraer, B. Cauberghe, P. Verboven, and J. Leuridan, Automative and aerospace applications of LMS PolyMAX modal parameter estimation method, Proceedings of IMAC 22, International Modal Analysis Conference, Dearborn (MI), USA, January 2004.

[3] B. Peeters And H. Van der auweraer:, PolyMAX: a revolution in Operational Modal Analysis, Proceedings of IOMAC, 1st International Operational Modal Analysis Conference, Copenhagen, Denmark, 26-27 April 2005.

[4] W. Heylen, S. Lammens, P. Sas, Modal Analysis Theory and Testing, Katholieke Universiteit Leuven, Departement Werktuigkunde, Leuven, 1997.

[5] B. Peeters, H. Van der Auweraer, F. Vanhollebeke. P. Guillaume, Operational modal analysis for estimating the dynamic properties of a stadium structure during a football game, Shock and Vibrations, Vol. 14, No 4, (2007),pp. 283-303.

[6] J. Debille, S. Pauwels, B. Peeters, The Benefits of Operational Modal Analysis of Aircraft and Spacecraft Structures, Proceedings of ETTC, European Test and Telemetry Conference, Toulouse, France, 7-9 June 2005.

[7] J. Jonkman, S. Butterfield, W. Musial, G. Scott, Definition of a 5-MW Reference Wind Turbine for Offshore System Development, NREL/TP-500-38060 Technical Report, USA, February 2009.

[8] LMS Samtech Iberica, Samtech for Wind Turbines V3.2.01 Online help, Spain, 2012.

[9] S. Manzato, D. Moccia, B. Peeters, K. Janssens, J.R. White, A Review of Harmonic Removal Methods for Improved Operational Modal Analysis of Wind Turbines, Proceedings of ISMA2012, International Conference on Noise and Vibration Engineering, Leuven, Belgium, 17-19 September 2012.

[10] M. Luczak, M. Firla, D. Sporna, S. Manzato, B. Peeters, Structural Monitoring of the swall wind turbine test stand, Proceedings of EURODYN 2011, $8^{\text {th }}$ International Conference on Structural Dynamics, Leuven, Belgium, 4-6 July 2011

[11] LMS International, LMS Test.Lab Rev. 12A User Manual, Belgium, 2012. 